\title{
Review
}

\section{of Psychopharmacological} Approaches

\section{for Trichotillomania and Other Body-Focused Behaviors}

\section{Jon E. Grant, J.D., M.D., M.P.H.}

\author{
Address \\ Department of Psychiatry and Behavioral Neuroscience, Pritzker School of \\ Medicine, University of Chicago, 5841 S. Maryland Avenue, MC 3077, \\ Chicago, IL, 60637, USA \\ Email: jongrant@uchicago.edu
}

Published online: 1 October 2015

(C) Springer International Publishing AG 2015

This article is part of the Topical Collection on Anxiety, Obsessive Compulsive and Related Disorders

Keywords Trichotillomania · Skin picking · Excoriation · Hair pulling · Pharmacology · Treatment

\section{Opinion statement}

$\mathrm{N}$-acetyl cysteine (NAC) is a safe, generally well-tolerated option for these disorders, and so I usually suggest a trial of NAC. If after 3 months and no response, I consider other options. If the person has urges to pull or pick and they have first-degree relatives with addictions, then I suggest a trial of naltrexone. If they have significant anxiety or depression co-occurring with the pulling, I often suggest clomipramine as a possible treatment for both conditions. In the case of skin picking with co-occurring depression or anxiety, I recommend a selective serotonin reuptake inhibitor (SSRI). Although we only have open-label data to support its use, I often use dronabinol in individuals who pick or pull most of the time unconsciously. Finally, I might suggest an antipsychotic for some people who have failed all else. Due to the side effects of antipsychotic medications, I use these only as a last resort.

\section{Introduction}

With prevalence rates estimated at 0.5 to $2.0 \%$ for trichotillomania and 1.4 to $5.4 \%$ for skin picking disorder, these body-focused repetitive behavior disorders (BFRBs) represent common and oftentimes disabling health problems [1-6]. Characterized by persistent and recurrent patterns of excessive grooming, trichotillomania, and skin picking disorder are frequently associated with impaired functioning, 
reduced quality of life, poor self-esteem, and even medical complications such as trichobezoars and infections [7-12]. Whereas trichotillomania usually has its onset in late childhood or early adolescence [13, $14]$, skin picking disorder has a more varied onset in either childhood, adolescence, or adulthood [8, 15]. Both disorders have been described as chronic, relapsing conditions, and both often have worsening symptom severity during times of stress, anxiety, or boredom $[8,14]$. Even though trichotillomania and skin picking disorder interfere with a person's quality of life, the majority (about $65 \%$ ) of individuals never seek treatment $[9,16]$.

Research into the neurobiology of BFRBs is still in an early stage, but our current understanding of these disorders owes much to understanding animal behaviors that are similar to BFRBs [17-19] and to the early human research in these disorders [20]. Although still incompletely understood, recent advances in the treatment of BFRBs show that trichotillomania and skin picking disorder can often be effectively treated with pharmacologic interventions.

\section{Neurobiology}

\section{Genetic vulnerability}

Although much remains unknown about the neurobiological underpinnings of BFRBs, recent genetic evidence suggests a complex picture for these two disorders. Trichotillomania appears to be familial with heritability estimates ranging from 0.32 to 0.78 [21, 22]. One study also found that $1.2 \%$ of twins ( $n=2518$ twins) from the UK Adult Twin Registry endorsed clinically significant skin picking and that additive and non-additive genetics factors accounted for more than $40 \%$ of the variance in picking [23]. While this research suggests that both disorders have familial aspects, a recent study questions whether a genetic link exists across BFRBs. A recent family study of 110 proband cases with trichotillomania, 128 first-degree relatives of the probands, 48 controls, and 50 first-degree relatives of the controls found that case versus control relatives had higher recurrence risk estimates for trichotillomania but not skin picking disorder [24]. These findings seem to support the idea that BFRBs may not simply be variants of the same disorder, and it also calls into question a shared biological relationship between these disorders. Although we currently tend to use the same pharmacological treatments for both disorders, this recent genetic and family data may suggest that different treatment could be necessary for different BFRBs.

Recent neuroimaging studies in trichotillomania have shed light on possible biological correlates to the behavior. Structural studies in trichotillomania have been largely mixed and suggest that the disorder may be more heterogeneous than initially thought. A study examining cortical thickness in 12 individuals with trichotillomania, their first-degree relatives $(n=10)$ and controls $(n=14)$ found excessive cortical thickness in probands and their relatives in brain regions associated with inhibitory control and action monitoring [25•]. A different study, however, found reduced cortical thickness in a different area (the right parahippocampal gyrus which is involved in memory and recogni-

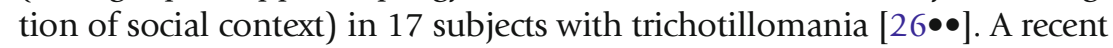
functional neuroimaging study found that 12 individuals with trichotillomania exhibited decreased activation of the nucleus accumbens when present with a 


\section{Treatment}

task of reward anticipation but showed increased activity when presented with gain and loss outcomes [27].

In the case of skin picking disorder, a recent structural study in 17 women with skin picking disorder found altered brain volume and cortical thickness in a number of frontal areas involved in habit formation, and these findings

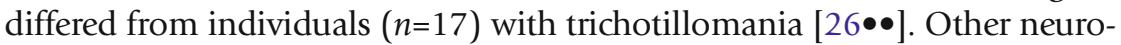
imaging studies, however, have found similar disorganization of white matter tracts underlying motor generation and suppression in both disorders [28, 29].

Taken together, the neuroimaging research suggests that dysfunction in circuits involved in top-down control may be implicated in BFRBs. Having said that, the various inconsistent findings in these studies suggest that there may be significant heterogeneity among individuals with the same disorder and in many cases, this may explain why findings between disorders have also been inconsistent.

Traditionally, trichotillomania and skin picking disorder have been treated with behavioral therapy, and two recent meta-analyses support the choice of behavioral therapy as the first-line treatment $[30,31]$. Emerging evidence, however, suggests that trichotillomania and skin picking disorder can be treated successfully with pharmacotherapy as well.

Although no pharmacotherapies are FDA-approved for trichotillomania or skin picking disorder, there have been 15 double-blind, placebo-controlled studies for these disorders (Table 1). Several important findings have emerged from these studies. First, serotonin reuptake inhibitors (clomipramine and the selective serotonin reuptake inhibitors [SSRIs]) have shown mixed results in studies, with clomipramine demonstrating some benefit for trichotillomania and the SSRIs showing some positive effects in skin picking disorder. Methodological problems with the skin picking studies and small sample sizes with the trichotillomania studies, however, limit the interpretation of these mixed results. It is possible therefore that some individuals with either of these disorders will respond to SSRIs, but the evidence as a whole does not suggest that they will be effective for the core symptoms of trichotillomania, except possibly clomipramine. In the case of skin picking, the SSRIs may be more beneficial but the studies are limited and all were conducted before there were clear diagnostic criteria for the disorder. It is also possible that the "response" many people derive from SSRIs is a reduction in their anxiety or an improvement in mood. As both anxiety and depression may worsen pulling or picking behavior, it stands that the SSRIs may indirectly be assisting with the BFRB behavior. In the case of trichotillomania, it does not seem that the SSRIs have any direct effect on the pulling in a majority of cases. In the case of skin picking disorder, SSRIs may be more beneficial.

The second important finding from these early studies was that behavioral therapy appears to be more effective than serotonergic antidepressant treatment. Two comparison studies have been conducted in trichotillomania. In the 


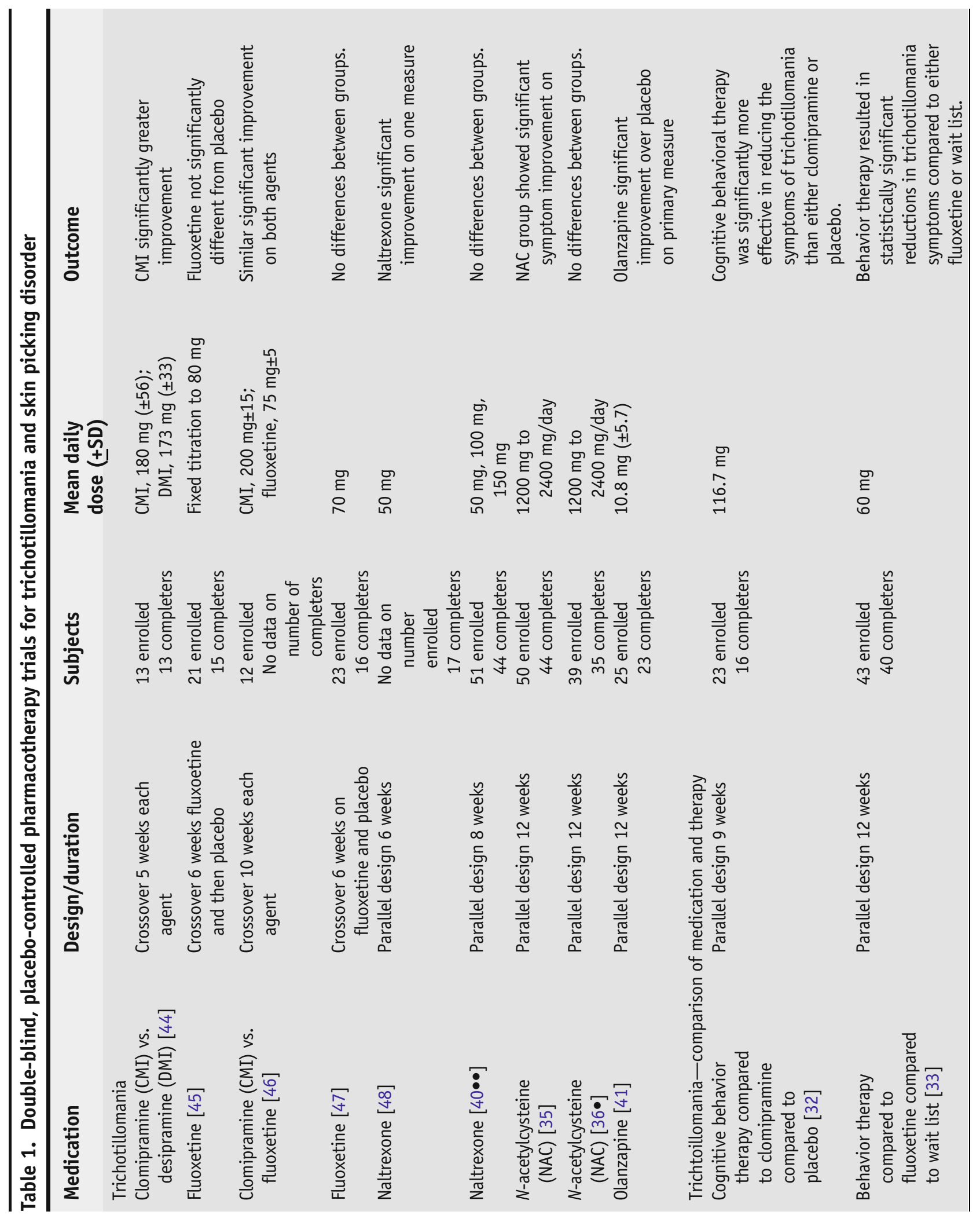




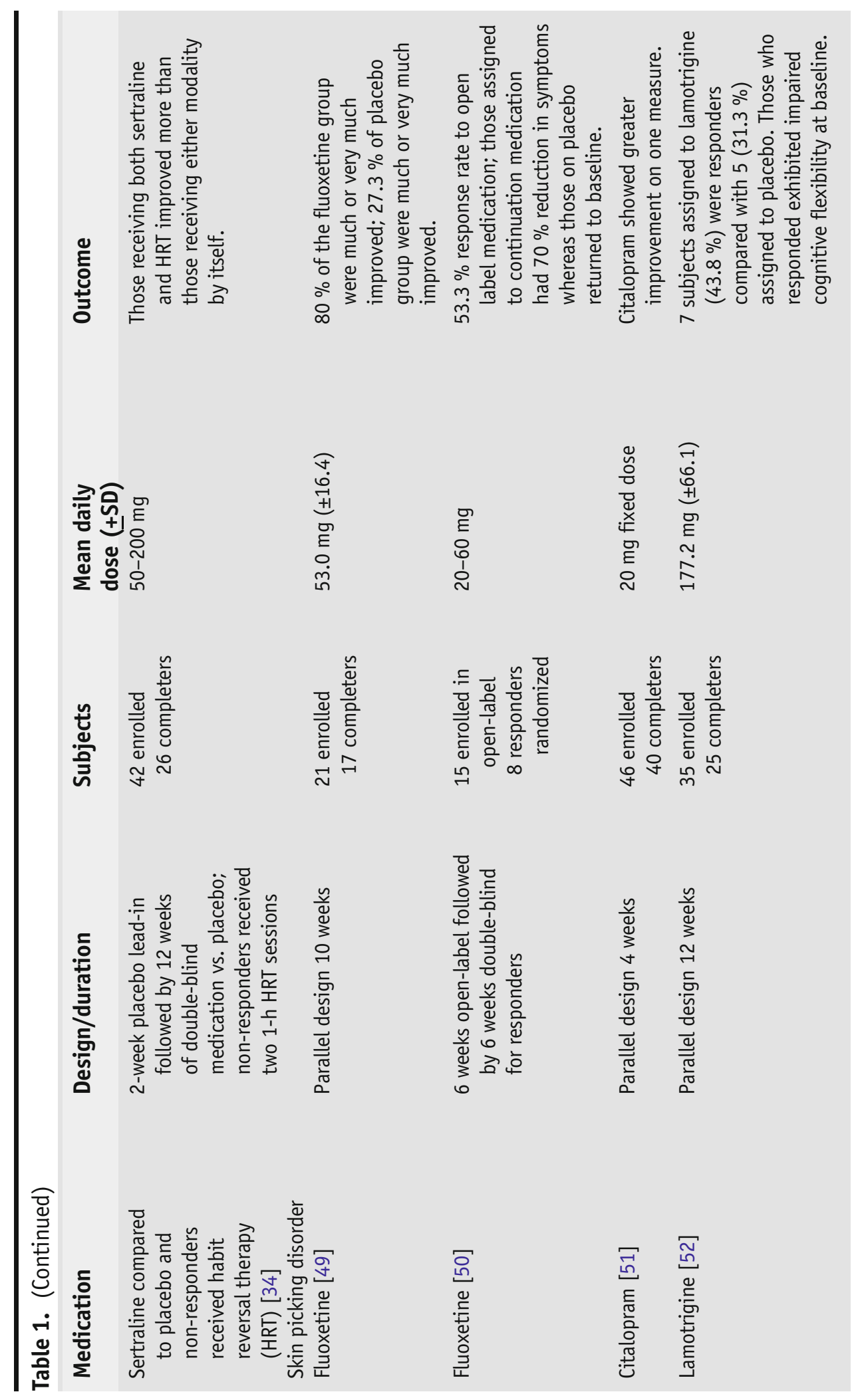


first study, clomipramine was compared to cognitive behavioral therapy (a modified form of habit reversal therapy) [32]. Cognitive behavioral therapy was significantly more effective in reducing the symptoms of trichotillomania than either clomipramine or placebo. In a second comparison study of fluoxetine with behavior therapy, behavior therapy resulted in statistically significant reductions in trichotillomania symptoms compared with either fluoxetine or wait-list [33]. One study, however, found that a combination of behavior therapy (habit reversal therapy) with a serotonergic antidepressant (sertraline) was more beneficial than either modality by itself [34].

Given the findings from these early studies examining antidepressant medications for BFRBs, recent pharmacotherapy research has shifted its focus to other agents. One area of particular interest has been glutamate agents such as $n$-acetylcysteine (NAC). A study of NAC versus placebo in 50 adults found that NAC was effective in reducing pulling episodes and improving the ability to resist the urge to pull [35]. A study in 39 children with trichotillomania, however, found no significant differences between NAC and placebo [36•]. The inconsistent findings from these two studies raise multiple questions that may prove useful in focusing treatment research. For example, are children with BFRBs different biologically from adults? Younger children with trichotillomania are generally less likely to report urges to pull, and this clinical phenomenon of urges seems to increase with age [37]. Therefore, perhaps NAC works best in individuals with BFRBs who report urges preceding their behavior. This would be consistent with the literature examining NAC in drug addiction [38]. If NAC works by reducing urges to pull or pick, then this might allow for clinical subtyping as a means of refining treatment approaches.

Other recent pharmacological research further supports subtyping individuals with BFRBs as a way to improve treatment outcomes. Opioid antagonists (e.g., naltrexone) are a class of medications that have been used successfully in animals with excessive grooming (for example, acral lick dermatitis in dogs) [39]. A recent double-blind placebo-controlled study of naltrexone in 52 adults with trichotillomania, however, demonstrated that naltrexone was no more successful than placebo in treating trichotillomania $[40 \bullet \bullet]$. A post hoc analysis found that naltrexone was more effective than placebo in those individuals with trichotillomania who exhibited cognitive inflexibility on testing (using the intradimensional/extradimensional shift task) and those who reported a family history of alcohol or substance use disorders in first-degree relatives $[40 \bullet \bullet]$.

Second-generation antipsychotics may also play a role in the treatment of BFRBs. An earlier study examining olanzapine in 25 adults with trichotillomania found that 11 of $13(85 \%)$ individuals assigned to olanzapine and only 2 of $12(17 \%)$ assigned to placebo responded to treatment [41]. Building upon this finding, a recent open-label study examining aripiprazole in 12 individuals with trichotillomania found it to be effective in 7 subjects (58\%) in reducing hair pulling frequency [42]. This latter study needs to be evaluated cautiously given the openlabel nature of the design. The two studies together not only suggest a potential role for antipsychotics in treating BFRBs but they also raise 
several questions. Given that not all antipsychotics have a similar mechanism of action, which ones would be most useful for BFRBs? In addition, if they are successful, mechanistically how are they helping? Is it possible that these medications dampen reward-driven behaviors through their effects on dopamine in the nucleus accumbens, and this would be consistent with one of the recent neuroimaging studies [27]. Further subtyping using fMRI may be promising to see who responds preferentially to certain antipsychotic medications.

Finally, other BFRB treatment studies are attempting to use findings from neuroimaging to enhance pharmacological approaches. The neuroimaging data in BFRBs suggest disorganization of white matter tracts in motor habit generation and suppression $[28,29]$. On a neurochemical level, these motor habits may rely at least partially on the endocannabinoid system. Thus, one study examined the cannabinoid agonist, dronabinol, in an open-label study of 14 individuals with trichotillomania. The study found that trichotillomania symptoms improved significantly in a majority (64.3\%) of subjects [43]. Future research may want to examine whether dronabinol works preferentially in individuals with BFRBs who also have disorganized white matter tracts in the relevant motor areas of the brain.

The results of all of these studies suggest that a single pharmacological treatment for everyone with trichotillomania and skin picking disorder is highly unlikely. Instead, identifying subtypes of individuals with BFRBs, using clinical, cognitive, and neuroimaging research, may allow for targeted and more effective pharmacotherapy.

Although there are several studies of pharmacotherapy for trichotillomania and skin picking disorder, the data are either limited or inconsistent. The two pharmacotherapies that have shown potential promise in treating adult trichotillomania in double-blind, placebo-controlled studies are NAC and olanzapine. Open-label studies show the promise of both aripiprazole and dronabinol in reducing trichotillomania symptoms. In addition, a single study suggests that medication in combination with behavioral therapy may be a more successful option than either one alone. In the case of skin picking, the SSRIs may play a role in treatment. Because different pharmacotherapies with different neurobiological mechanisms of action (glutamate in the nucleus accumbens, dopamine blockade, cannabinoid agonism, serotonergic tone) have all shown promise for BFRBs, these findings force us to consider whether there may be meaningful subtypes of BFRBs with different pathophysiologies. If that is the case, then pharmacological interventions will need to be individually tailored based on this information.

In the area of BFRBs, the systematic study of treatment efficacy and tolerability is in its infancy. With few studies published, and none that have been successfully replicated by other investigators, it is not possible to make treatment recommendations with a substantial degree of confidence. Nonetheless, specific drug therapies offer promise for the effective treatment of BFRBs.

However, most published studies have employed relatively small sample sizes, are of limited duration, and involve possibly non-representative clinical groups 
(e.g., those without co-occurring psychiatric disorders). In addition, heterogeneity of treatment samples may also complicate identification of effective treatments. At present, issues such as which medication to use and for whom cannot be sufficiently addressed with the available data.2333

\section{Compliance with ethics guidelines}

\section{Conflict of Interest}

With respect to the content of this article, Dr. Grant has received research grants from NIMH, National Center for Responsible Gaming, Brainsway, and Forest and Roche Pharmaceuticals. He receives yearly compensation from Springer Publishing for acting as Editor-in-Chief of the Journal of Gambling Studies and has received royalties from Oxford University Press, American Psychiatric Publishing, Inc., Norton Press, and McGraw Hill.

\section{Human and animal rights and informed consent}

This article contains studies with human subjects performed by the author $[11,25 \bullet, 29,35,40 \bullet \bullet, 43,52]$. For each study, the Institutional Review Board of the University of Minnesota or the University of Chicago approved the study, and all procedures were carried out in accordance with the Declaration of Helsinki.

\section{References}

Papers of particular interest, published recently, have been

highlighted as:

- Of importance.

- Of major importance

1. Christenson GA, Pyle RL, Mitchell JE. Estimated lifetime prevalence of trichotillomania in college students. J Clin Psychiatry. 1991;52(10):415-7.

2. King RA, Zohar AH, Ratzoni G, Binder M, Kron S, Dycian A, et al. An epidemiological study of trichotillomania in Israeli adolescents. J Am Acad Child Adolesc Psychiatry. 1995;34:1212-5.

3. Duke DC, Bodzin DK, Tavares P, Geffken GR, Storch EA. The phenomenology of hairpulling in a community sample. J Anxiety Disord. 2009;23(8):118-1125.

4. Hayes SL, Storch EA, Berlanga L. Skin picking behaviors: an examination of the prevalence and severity in a community sample. J Anxiety Disord. 2009;23:314-9.

5. Keuthen NJ, Koran LM, Aboujaoude E, Large MD, Serpe RT. The prevalence of pathological skin picking in US adults. Compr Psychiatry. 2010;51:183-6.

6. Leibovici V, Murad S, Cooper-Kazaz R, Tetro T, Keuthen NJ, Hadayer N, et al. Excoriation (skin picking) disorder in Israeli University students: prevalence and associated mental health correlates. Gen Hosp Psychiatry. 2014;36(6):686-9.

7. Diefenbach GJ, Tolin DF, Hannan S, Crocetto J, Worhunsky P. Trichotillomania: impact on psychosocial functioning and quality of life. Behav Res Ther. 2005;43(7):869-84.

8. Grant JE, Odlaug BL, Chamberlain SR, Keuthen NJ, Lochner C, Stein DJ. Skin picking disorder. Am J Psychiatry. 2012;169:1143-9.

9. Tucker BT, Woods DW, Flessner CA, Franklin SA, Franklin ME. The skin picking impact project: phenomenology, interference, and treatment utilization of pathological skin picking in a population-based sample. J Anxiety Disord. 2011;25:88-95.

10. Flessner CA, Woods DW. Phenomenological characteristics, social problems, and the economic impact associated with chronic skin picking. Behav Modif. 2006;30:944-63.

11. Odlaug BL, Grant JE. Clinical characteristics and medical complications of pathologic skin picking. Gen Hosp Psychiatry. 2008;30(1):61-6.

12. Gaillard $M$, Tranchart $H$. Images in clinical medicine. Trichobezoar. N Engl J Med. 2015;372(6), e8.

13. Lewin AB, Piacentini J, Flessner CA, Woods DW, Franklin ME, Keuthen NJ, et al. Stein DJ; TLC-SAB. Depression, anxiety, and functional impairment in children with trichotillomania. Depress Anxiety. 2009;26(6):521-7.

14. Christenson GA, Mansueto CS. Trichotillomania: descriptive characteristics and phenomenology. In: Stein DJ, Christianson GA, Hollander E, editors. 
Trichotillomania. Washington, DC: American Psychiatric Press; 1999. p. 1-41.

15. Odlaug BL, Grant JE. Pathologic skin picking. In: Grant JE, Stein DJ, Woods DW, Keuthen NJ, editors. Trichotillomania, skin picking and other body-focused repetitive behaviors. Washington DC: American Psychiatric Publishing, Inc; 2012. p. pp 21-41.

16. Woods DW, Flessner CA, Franklin ME, Keuthen NJ, Goodwin RD, Stein DJ, et al. The Trichotillomania Impact Project (TIP): exploring phenomenology, functional impairment, and treatment utilization. J Clin Psychiatry. 2006;67:1877-88.

17. Garner JP, Thogerson CM, Dufour BD, Würbel H, Murray JD, Mench JA. Reverse-translational biomarker validation of abnormal repetitive behaviors in mice: an illustration of the $4 \mathrm{P}^{\prime} \mathrm{s}$ modeling approach. Behav Brain Res. 2011;219(2):189-96.

18. Chen SK, Tvrdik P, Peden E, Cho S, Wu S, Spangrude G, et al. Hematopoietic origin of pathological grooming in Hoxb8 mutant mice. Cell. 2010;141(5):775-85.

19. Camilla d'Angelo LS, Eagle DM, Grant JE, Fineberg NA, Robbins TW, Chamberlain SR. Animal models of obsessive-compulsive spectrum disorders. CNS Spectr. 2014;19(1):28-49.

20. Chamberlain SR, Odlaug BL, Boulougouris V, Fineberg NA, Grant JE. Trichotillomania: neurobiology and treatment. Neurosci Biobehav Rev. 2009;33(6):83142.

21. Novak CE, Keuthen NJ, Stewart SE, Pauls DL. A twin concordance study of trichotillomania. Am J Med Genet B Neuropsychiatr Genet. 2009;150B(7):944-9.

22. Monzani B, Rijsdijk F, Harris J, Mataix-Cols D. The structure of genetic and environmental risk factors for dimensional representations of DSM-5 obsessivecompulsive spectrum disorders. JAMA Psychiatry. 2014;71(2):182-9.

23. Monzani B, Rijsdijk F, Cherkas L, et al. Prevalence and heritability of skin picking in an adult community sample: a twin study. Am J Med Genet B

Neuropsychiatr Genet. 2012;159B(5):605-10.

24. Keuthen NJ, Altenburger EM, Pauls D. A family study of trichotillomania and chronic hair pulling. Am J Med Genet B Neuropsychiatr Genet. 2014;165B(2):167-74. This is the first detailed family study of trichotillomania using a control group.

25. Odlaug BL, Chamberlain SR, Derbyshire KL, Leppink EW, Grant JE. Impaired response inhibition and excess cortical thickness as candidate endophenotypes for trichotillomania. J Psychiatr Res. 2014;59:167-73.

This study reports evidence for a familial cognitive vulnerability to trichotillomania.

26.• Roos A, Grant JE, Fouche JP, Stein DJ, Lochner C. A comparison of brain volume and cortical thickness in excoriation (skin picking) disorder and trichotillomania (hair pulling disorder) in women. Behav Brain Res. 2015;279:255-8.

First international comparison study of the biology of trichotillomania and skin picking.
27. White MP, Shirer WR, Molfino MJ, Tenison C, Damoiseaux JS, Greicius MD. Disordered reward processing and functional connectivity in trichotillomania: a pilot study. J Psychiatr Res. 2013;47(9):1264-72.

28. Chamberlain SR, Hampshire A, Menzies LA, Garyfallidis E, Grant JE, Odlaug BL, et al. Reduced brain white matter integrity in trichotillomania:a diffusion tensor imaging study. Arch Gen Psychiatry. 2010;67(9):965-71.

29. Grant JE, Odlaug BL, Hampshire A, Schreiber LR, Chamberlain SR. White matter abnormalities in skin picking disorder: a diffusion tensor imaging study. Neuropsychopharmacology. 2013;38(5):763-9.

30. McGuire JF, Ung D, Selles RR, Rahman O, Lewin AB, Murphy TK, et al. Treating trichotillomania: a metaanalysis of treatment effects and moderators for behavior therapy and serotonin reuptake inhibitors. J Psychiatr Res. 2014;58:76-83.

31. Rothbart R, Amos T, Siegfried N, Ipser JC, Fineberg N, Chamberlain SR, et al. Pharmacotherapy for trichotillomania. Cochrane Database Syst Rev. 2013;11, CD007662.

32. Ninan PT, Rothbaum BO, Marsteller FA, Knight BT, Eccard MB. A placebo-controlled trial of cognitivebehavioral therapy and clomipramine in trichotillomania. J Clin Psychiatry. 2000;61(1):47-50.

33. van Minnen A, Hoogduin KA, Keijsers GP, Hellenbrand I, Hendriks GJ. Treatment of trichotillomania with behavioral therapy or fluoxetine: a randomized, waiting-list controlled study. Arch Gen Psychiatry. 2003;60(5):517-22.

34. Dougherty DD, Loh R, Jenike MA, Keuthen NJ. Single modality versus dual modality treatment for trichotillomania: sertraline, behavioral therapy, or both? J Clin Psychiatry. 2006;67:1086-92.

35. Grant JE, Odlaug BL, Kim SW. N-acetylcysteine, a glutamate modulator, in the treatment of trichotillomania: a double-blind, placebo-controlled study. Arch Gen Psychiatry. 2009;66(7):756-63.

36. Bloch MH, Panza KE, Grant JE, Pittenger C, Leckman JF. N-Acetylcysteine in the treatment of pediatric trichotillomania: a randomized, double-blind, placebo-controlled add-on trial. J Am Acad Child Adolesc Psychiatry. 2013;52(3):231-40.

First pharmacological study in children.

37. Panza KE, Pittenger C, Bloch MH. Age and gender correlates of pulling in pediatric trichotillomania. J Am Acad Child Adolesc Psychiatry. 2013;52(3):241-9.

38. Asevedo E, Mendes AC, Berk M, Brietzke E. Systematic review of $\mathrm{N}$-acetylcysteine in the treatment of addictions. Rev Bras Psiquiatr. 2014;36(2):168-75.

39. Dodman NH, Shuster L, White SD, Court MH, Parker D, Dixon R. Use of narcotic antagonists to modify stereotypic self-licking, self-chewing, and scratching behavior in dogs. J Am Vet Med Assoc. 1988;193(7):815-9.

$40 . \bullet$ Grant JE, Odlaug BL, Schreiber LR, Kim SW. The opiate antagonist, naltrexone, in the treatment of 
trichotillomania: results of a double-blind, placebocontrolled study. J Clin Psychopharmacol. 2014;34(1):134-8.

First pharmacological study to demonstrate the utility of subtyping individuals based on cognitive profiles.

41. Van Ameringen M, Mancini C, Patterson B, Bennett M, Oakman J. A randomized, double-blind, placebocontrolled trial of olanzapine in the treatment of trichotillomania. J Clin Psychiatry. 2010;71(10):1336-43.

42. White MP, Koran LM. Open-label trial of aripiprazole in the treatment of trichotillomania. J Clin

Psychopharmacol. 2011;31(4):503-6.

43. Grant JE, Odlaug BL, Chamberlain SR, Kim SW. Dronabinol, a cannabinoid agonist, reduces hair pulling in trichotillomania: a pilot study. Psychopharmacology (Berl). 2011;218(3):493-502.

44. Swedo SE, Leonard HL, Rapoport JL, Lenane MC, Goldberger EL, Cheslow DL. A double-blind comparison of clomipramine and desipramine in the treatment of trichotillomania (hair pulling). N Engl J Med. 1989;321(8):497-501.

45. Christenson GA, Mackenzie TB, Mitchell JE, Callies AL. A placebo-controlled, double-blind crossover study of fluoxetine in trichotillomania. Am J Psychiatry. 1991;148(11):1566-71.

46. Pigott TA, L'Heueux F, grady TA. Controlled comparison of clomipramine and fluoxetine in trichotillomania. In Abstracts of the 31st Annual Meeting of the
American College of Neuropsychopharmacology, San Juan, Puerto Rico, December, 1992, p.157.

47. Streichenwein SM, Thornby JI. A long-term, doubleblind, placebo-controlled crossover trial of the efficacy of fluoxetine for trichotillomania. Am J Psychiatry. 1995;152(8):1192-6.

48. O'Sullivan RL, Christenson GA, Stein DJ. Pharmacotherapy of trichotillomania. In: Stein DJ, Christianson GA, Hollander E, editors. Trichotillomania. Washington, DC: American Psychiatric Press; 1999. p. pp 93123.

49. Simeon D, Stein DJ, Gross S, Islam N, Schmeidler J, Hollander E. A double-blind trial of fluoxetine in pathologic skin picking. J Clin Psychiatry. 1997;58(8):341-7.

50. Bloch MR, Elliott M, Thompson H, Koran LM. Fluoxetine in pathologic skin-picking: open-label and doubleblind results. Psychosomatics. 2001;42(4):314-9.

51. Arbabi M, Farnia V, Balighi K. Efficacy of citalopram in the treatment of pathological skin picking: a randomized double blind placebo controlled trial. Acta Med Iran. 2008;46:367-72.

52. Grant JE, Odlaug BL, Chamberlain SR, Kim SW. A double-blind, placebo-controlled trial of lamotrigine for pathological skin picking: treatment efficacy and neurocognitive predictors of response. J Clin Psychopharmacol. 2010;30(4):396-403. 